\title{
APRESENTAÇÃO
}

\section{DOSSIÊ PAULO FREIRE E O NEOCONSERVADORISMO}

\author{
PAULO FREIRE AND THE NEOCONSERVATIVE WAVE
}

(Dosé Eustáquio Romão

Doutor em Educação, Diretor e Professor do Programa de Pós-Graduação em Educação, da Universidade Nove de Julho (PPGE-UNINOVE); Diretor Fundador do Instituto Paulo Freire e Secretário Geral; do Conselho Mundial dos Institutos Paulo Freire. jerromao@gmail.com

Maurício Pedro da Silva Doutor em Letras e Professor do Programa de Pós-Graduação da Universidade Nove de Julho (PPGEUNINOVE), onde é líder da Linha de Pesquisas Educação Popular e Culturas (LIPEPCULT). maurisil@gmail.com

\section{Para citar - (ABNT NBR 6023:2018)}

ROMÃO, José Eustáquio; SILVA, Maurício Pedro da. Apresentação Paulo Freire e o neoconservadorismo. Eccos - Revista Cientifica, São Paulo, n. 52, p. 1-05, jan./mar. 2020. Disponível em: https://doi.org/10.5585/eccos.n52.17092.

Organizar um dossiê pode parecer uma tarefa banal, mas não é. Primeiramente há que se formular um projeto editorial, com um eixo temático estruturante comum e que seja atraente e facilmente inteligível, para que os autores que escreverão os artigos não percam o rumo do caminho que se pretende palmilhar. Depois, vêm os clamores constrangedores pelos prazos limites, o ir e vir dos textos dos editores para os pareceristas e para os próprios autores, as revisões, a diagramação, a elaboração da apresentação e, finalmente a diagramação e, novamente as idas e vindas dos texto até a sua publicaçnao final. No caso deste dossiê, todo o mencionado labor levou mais de ano.

No caso deste dossiê, o trabalho ficou bem mais amenizado por causa de sua organização ter sido compartilhada e porque se contou com uma plêiade de pesquisadoresarticulistas do mais alto gabarito acadêmico. Dos convidados - quase todos do exterior - a adesão foi imediata, certamente por causa do tema: "Paulo Freire e o Neoconservadorismo".

O dossiê se inicia, exatamente, pelo texto homônimo do Prof. Dr. José Eustáquio Romão que, de uma certa maneira, dá o tom da orientação encaminhada aos articulistas convidados: o conservadorismo que grassou e se tornou expressivo em vários países do mundo, com uma nova 
cara "tecnologizada", porque usando, de modo competente, as novas tecnologias da informação e da comunicação (TICs), especialmente pelas popularmente conhecidas como "redes sociais". Acabaram arrastando multidões, como foi o caso do Brasil nas últimas eleições presidenciais. Este primeiro texto tenta dar uma racionalidade à compreensão do fenômeno que, segundo seu autor, não chama a atenção por suas bizarras lideranças, mas pela expressiva massa de seguidores que, na maioria das vezes, passa a mitologizar como líderes seus potenciais algozes. $\mathrm{O}$ autor deste primeiro artigo tenta demonstrar a atualidade do pensamento de Paulo Freire cuja obra mais conhecida, Pedagogia do oprimido, completa o cinquentenário de sua primeira edição, além de ter seus originais manuscritos recentemente resgatados e publicados (2018) -, no sentido de se contrapor e iluminar um pouco a área obscurecida por essa espécie de "Neoconservadorismo", que ele grafa com maiúscula.

O segundo trabalho, consubstanciado no artigo de Ana Ayuste González e de Jaume Trilla I Bernet, ambos da Universidade de Barcelona, demonstra como Freire foi e continua sendo importante para os educadores espanhóis, especialmente os catalães, na luta contra o conservadorismo em um país que teve uma das mais longevas ditaduras do século $\mathrm{XX}$, o "Franquismo", e que tem de continuar lutando contra as investidas do Neoconservadorismo. O texto trata tanto das visitas pessoais de Freire e suas alocuções, nas oportunidades em que esteve na Espanha, mais especificamente na Catalunha, de cuja Universidade recebeu o título de Doutor honoris causa há mais de três décadas. Em outro sentido, o artigo de Ana e Jaume alerta para os perigos de um possível "sectarismo freiriano" - tendência que Freire rechaçava terminantemente, quando estabelecia a diferença entre radicalismo e sectarismo -, que tenta mitologizar também o legado de Freire. Ademais, o artigo é enriquecido por cópia de imagens de Freire e de documentos de notável valor histórico.

O trabalho de Irène Pereira, coordenadora do Instituto Paulo Freire da França, demonstra o progressismo da proposta freiriana na atualidade, depois de ela ter caído em um relativo esquecimento até cerca de 2015, a despeito de sua expressividade nos anos 70 do século XX, certamente aí favorecia pela proximidade pessoal de Freire no exílio em Genebra (Suíça). E, segundo a autora, Freire apresenta-se, hoje em dia, como uma das possíveis respostas às perplexidades provocadas por um contexto neoconservador e neoliberal também presente no contexto francês, desde os discursos de suas autoridades maiores até o interior do imaginário de segmentos sociais “esclarecidos". Os dois lados de Freire se revelam e se iluminam no artigo dessa jovem brilhante filósofa/socióloga e militante franco-brasileira ${ }^{1}$ : a produção intelectual e a militância política. Não deixam de ser reveladoras as considerações de Irène a respeito do pensamento de Freire em relação aos feminismos e às questões de gênero. 
Peter Lownds, um velho amigo do Brasil e seguidor do legado emancipatório de Freire, como artista que é, desvenda, no artigo, o caráter revolucionário do "romantismo freiriano". Lownds, que deixou as luzes dos palcos nova-iorquinos e dos sets cinematográficos de Hollywood para se dedicar à educação de adultos na periferia de Los Angeles, reconstitui, de modo inusitado e estético, a biografia do itinerante perseguido e exilado Paulo Freire que, mesmo "sem pátria" - proibido de voltar ao próprio país natal e sem passaporte - não perdeu a esperança na capacidade transformadora da utopia. Segundo Peter Lownds, a "utopia romântica" realista de Freire, que tem seus antecedentes na vida e obra de outro sonhador, William Morris (1834-1896), foi e continua sendo uma de suas ferramentas mais importantes da luta contra as trevas do Neoconservadorismo, erigindo-se como luzeiro da libertação humana dos grilhões da opressão. Escreve ele: “Como Jean-Jacques Rousseau e William Morris, Paulo Freire é um socialista romântico cujos escritos, muitas vezes, contêm, descrições íntimas de seres humanos em crise..." (v. p. 13 do artigo). Lownds conclui o trabalho relacionando Freire a românticos revolucionários mais antigos, como Jean-Jacques Rousseau e William Morris, bem como aos mais novos, como João Francisco de Souza (de saudosa memória) e Danilson Pinto - estes educadores populares comprometidos com os mais oprimidos do Brasil.

Além dos convidados, os editores da revista Eccos abriram um edital de chamada e "choveram" artigos de todos os lados. Os organizadores do dossiê tivemos um trabalho imenso para selecionar, penalizados, apenas dois das mais de três dezenas de artigos apresentados ao edital (o dossiê se completaria com seis trabalhos) ${ }^{2}$.

O primeiro deles, de autoria de Ana Claudia Ferreira Godinho, Elionaldo Fernandes Julião e Elenice Cammarosano Onofre, resulta das largas experiências e das reflexões que estes pesquisadores e ativistas têm, respectivamente, com o trabalho educacional com os segmentos demográficos privados da liberdade por condenação do aparato jurídico e dos aparelhos repressores do Estado brasileiro e com as reflexões pedagógicas sobre tal trabalho. A questão axial que fazem de partida é: "É possível a educação, em contextos de privação de liberdade, constituir-se como educação dialógica, como prática de liberdade?”. Ambas as categorias, dialogicidade e prática da liberdade são nitidamente da lavra de Paulo Freire e são fundamentais para o Patrono da Educação Brasileira enquanto ideais da ação educacional e da reflexão pedagógica. Os autores entendem que, embora privados do direito de ir e vir, as pessoas com privação de liberdade continuam como sujeitos de direitos, a despeito dos preconceitos vigentes na sociedade brasileira e, por isso, as mencionadas categorias freirianas, apesar de aparentemente contraditórias com a situação desses segmentos demográficos, são profundamente adequadas e oportunas. Dentre os direitos a serem destacados está o direito à 
educação, do qual os encarcerados e os jovens em conflito com a lei não podem ser privados. Ressaltam ao autores ainda que, em tempos de Neoconservadorismo e de Neoliberalismo, as potencialidades da educação freiriana ficam mais ameaçadas e que, por isso, é preciso reaviválas com ênfase. Poder-se-ia acrescentar ao que propõem os articulistas deste trabalho as possibilidades da chamada “Justiça Restaurativa”, que já está implantada em alguns setores do aparato jurídico-político brasileiro há mais de uma década ${ }^{3}$ e que vem dando resultados muito interessantes em outros países, como a Nova Zelândia, Canadá e Estados Unidos. No Brasil, a Justiça Restaurativa vem oferecendo alternativas interessantes ao Direito Punitivo, especialmente em relação à mediação e formação de jovens em conflito com a lei.

O último trabalho, também resultante da "chamada pública" feita pelos editores da Eccos, vem de uma "dobradinha" de uma pesquisadora brasileira e de uma argentina, que objetivaram analisar o que denominam "re/ex/istência freiriana" diante do obscurantismo que paira no Brasil e na Argentina e que que tem hegemonizado e infernizado a vida dos mais oprimidos nesses países, nesses novos tempos de Neoconservadorismo. Com o que Manuel Castells chama de "ditadura das mentes" e Samir Naïr denomina "populismo nacional neofascista", as autoras alertam para as novas modalidades de autocracia da contemporaneidade nos dois países, carregada de ódio e, por via de consequência, provocadora de medo e, no limite, de pânico, nos segmentos mais fragilizados dos grupos étnicos dominados (feministas, pertencentes ao movimento LGBTQIA etc). Contudo, o que as autoras querem focalizar é a irracional aversão aos conceitos, categorias, posições e propostas, em síntese, ao legado de Paulo Freire, materializada em um verdadeiro "programa governamental" que se caracteriza por um conjunto de "bandeiras ideológicas de espectro ultradireitista" (p. 3 do artigo). E isso, no país em que Paulo Freire foi proclamado legalmente como Patrono da Educação Brasileira ${ }^{4}$. Aliás, o "gabinete do ódio" - como vem sendo denominada popularmente a ala ultraconservadora dos apoiadores do Governo de Jair Bolsonaro - tentou cassar esse título concedido a Freire (in memoriam), mas foi derrotado pela reação dos movimentos populares da educação, encabeçados pelo Instituto Paulo Freire. No artigo, as autoras fazem referência a todos os movimentos direitistas que vêm ocorrendo no campo da educação no Brasil (Escola Sem Partido, Movimento Brasil Livre, denúncia de educadores progressistas etc.). E, neste aspecto, as autores concluem: "En resumen, el pensamiento de Freire hoy, en Brasil, confronta un proyecto de gobernanza de mentes y cuerpos, precisamente al activar modos plurales de existencia y resistencia a formas de opresión, a través del diálogo y la esperanza de un mundo más justo para todos"5 (p. 7 do artigo). Na Argentina, continuam as autoras, o pensamento libertário de Paulo Freire continua ameaçado pelas políticas “necrocapitalistas". Também na 
Argentina, como em outros países da América Latina, o pretenso "consenso neoliberal", ainda que não tenha se tornado consenso concreto, suas pautas tornaram-se hegemônicas e, por via de consequência, o legado freiriano se vê a todo momento confrontado e agredido. $\mathrm{O}$ trabalho se conclui por uma análise do contexto ideológico na Universidad Nacional del Nordeste (UNNE) da Argentina, que não detalharemos aquí para que os leitores tenham o gosto de "saboreá-lo" no próprio texto.

Em conclusão, o dossiê parece ter cumprido, e até mesmo ultrapassado, os objetivos a que se propôs, pois logrou levantar estudos de uma série de países, sejam europeus, sejam latino-americanos, nos quais se estabelece, hoje, uma tensão entre o pensamento de Paulo Freire e as propostas neoliberais e neoconservadoras no campo da educação. Os exemplos contidos nas narrativas dos autores dos artigos deixam entrever que a esperança não tem sido uma espera vã, mas que está mais viva do que nunca, como ativa utopia alimentada pela seiva das categorias freirianas, que não são meras reflexões teóricas, mas verdadeiras e concretas feerramentas de luta por um mundo onde ainda seja possível amar.

\footnotetext{
${ }^{1} \mathrm{O}$ sobrenome Pereira revelam sua ascendência luso-brasileira.

${ }^{2}$ Evidentemente, os demais artigos apresentados passaram a fazer parte de um estoque do periódico e, certamente dentre eles, outros serão escolhidos para futuras publicações, dada sua qualidade.

${ }^{3}$ No PPGE-UNINOVE há um Grupo de Pesquisa, denominado "Justiça Dialógica", registrado no Conselho Nacional de Desenvolvimento Científico e Tecnológico (CNPq), que vem desenvolvendo estudos e pesquisas sobre essa contemporânea modalidade de Direito Penal, visando "contaminar" todo o direito burguês com suas potencialidade humanitárias e civilizatórias.

${ }^{4}$ Pela Lei n. ${ }^{\circ}$ 12.612, de 13 de abril de 2012, Paulo Freire foi proclamado Patrono da Educação Brasileira.

5 "Em resumo, o pensamento de Freire, hoje, no Brasil, confronta um projeto de governança de mentes e corpos, precisamente por ativar modos plurais de existência e resistência a formas de opressão, por meio do diálogo e da esperança em um mundo mais justo para todos.” (Tradução de J. E. Romão).
} 